\title{
Secularidade e sacralidade na criação musical contemporânea: tensões e transações
}

Alfredo Teixeira'

\section{Resumo}

Depois de um período em que a secularização, como modelo explicativo - linear e teleológico -afirmou-se hegemonicamente nas ciências sociais, tornou-se necessário encontrar outras vias de acesso aos lugares de reconfiguração do religioso, no contexto das múltiplas modernidades. Nesta situação, tornou-se decisivo reaproximar o olhar científico, em diferentes escalas, dos lugares em que estão a ser construídas novas relações entre a esfera do religioso e os outros mundos sociais, mediadas pelas deslocações do sagrado. O presente artigo explora o terreno da criação musical contemporânea como laboratório para a descoberta destas novas configurações.

Palavras-chave: Secularidade. Sacralidade. Música. Religião.

\section{Introdução}

Parte dos discursos sociológicos sobre a secularização, hegemônicos até à década de 90 do século passado, enfrentou o risco de se tornar uma teoria da religiáo legitimadora das narrativas da modernidade. $\mathrm{O}$ uso musculado desse modelo conheceu o seu revés à medida que se fragilizaram as próprias representaçóes de modernidade. Continuando a categoria de secularização a descrever trajetórias de mudança decisivas nas sociedades, perdeu, no entanto, o seu caráter linear e teleológico. No terreno das práticas culturais que descrevem as modernidades múltiplas, a esfera religiosa e os outros mundos sociais desdobram-se em jogos de transação, entre secularidades e sacralidades, na construçáo de sentidos e valores. Os universos da criaçấo musical contemporânea oferecem-se como um laboratório privilegiado para a moldagem de um modelo de secularização em modo menor (PIETTE, 1992).

\footnotetext{
Doutorado em Antropologia Política e Professor Auxiliar na Universidade Católica Portuguesa, onde é Diretor do Instituto de Estudos de Religião. É investigador do Centro de Estudos de Teologia e Estudos de Religião e do Centro de Estudos de História Religiosa (UCP).
} 


\section{Arquipélagos teóricos}

No breve ensaio intitulado "Excurso", bem como na sua "Sociologia da religião" - texto incluído em "Economia e Sociedade" - Weber parte da sua tese, já muito glosada, acerca da atividade religiosa como origem de processos de racionalização, em uma trajetória de superação do estádio mágico. Neste percurso, Weber procura mostrar que as relaçóes religião-mundo estão habitadas por uma lógica de "tensão" e "conflito". Esta lógica é particularmente visível em cinco esferas da realidade, registo em que as afinidades dos diferentes domínios sociais são, elas próprias, geradoras de tensôes: a esfera econômica, a esfera da política, o domínio da erótica, o que Weber designa de esfera intelectual e, por fim, a esfera estética.

Max Weber parte da observação genérica de que das transações entre religião e estética nasceram algumas das mais influentes criaçóes da humanidade. Mas, à medida que a arte foi construindo a sua autonomia, desenvolveram-se tensôes que Weber vê cristalizadas no díptico "conteúdo/forma”. Por um lado, as religiốes de salvação desenvolveram-se historicamente como conjuntos complexos de atribuição de sentido à experiência do mundo (conteúdo). Por sua vez, a arte, emergindo com funçóes análogas, conheceu novos contextos que facilitaram a emancipação da forma. A moderna possibilidade de desarticulação entre forma e conteúdo, segundo Weber, encontra no esteticismo o seu mais claro testemunho. Com este conceito, Max Weber procura interpretar as situações culturais em que a hipervalorização da experiência estética do mundo pode ser simultaneamente um substituto da religiáo e um refúgio intelectual para os desiludidos dos excessos racionalistas. $\mathrm{O}$ esteticismo seria, assim, uma espécie de "redenção intramundana". De acordo com Weber (1971, p. 554 ss; 1985, p. 365), o esteticismo substitui os juízos éticos por juízos estéticos.

A chamada Escola de Frankfurt tornou-se, nos circuitos do pensamento contemporâneo, uma bandeira do reformismo moderno, no sentido de recuperação de uma modernidade "espiritual", em detrimento dessa modernidade "material" radicalizada e reduzida ao mercado e aos impulsos da tecnociência. No campo da estética musical, esta herança crítica encontra no pensamento de Theodor Adorno as suas referências mais importantes. Por isso, ele se tornou uma influência fundamental na vanguarda do pós-guerra, nessa linha de 
legitimação de uma atitude de permanente procura do novo e a afirmação do anticonvencionalismo como uma garantia de validade estética e afastamento da música de massas. Adorno via a vanguarda (representada pela "nova música", emblematizada na chamada "Segunda Escola de Viena") como a possibilidade de fuga da mercantilização capitalista do produto estético. Para Adorno (1994), a autenticidade da arte tem uma relação de proporção inversa com a sua fruição, incentivando neste sentido, a composição de música sem motivaçóes externas. Estamos, pois, perante a afirmação de uma radical emancipação do ato de criação musical - Erwartung, de Schoenberg, na sua liberdade atonal e não serial, é, para Adorno, um modelo; Stravinsky, enquanto utilizador do passado, é, neste discurso, um contratipo.

Estamos, assim, no universo da crença moderna na força da revolução, enquanto crítica das funçóes normalizadoras da tradição. A relação com o material recebido assume a forma de ironia, sátira, distanciamento, por vezes por meio da citação ou da montagem, às vezes pela negação, sempre mediante um processo de recontextualização, com consequências no nível da estrutura. Mas, segundo Adorno, apenas na vanguarda se pode encontrar a interiorização e o desenvolvimento extremo da autonomia musical. A arte que se tornasse sistema, que substituísse o conceito pela fórmula, que fizesse da técnica ou do meio um fim e desistisse das ideias, negava a sua própria essência como arte. ${ }^{2}$

Adorno considerava a música de Alban Berg aquela que melhor podia representar "a memória da unidade originária do ser humano e da natureza", e propunha agora que a nova música devia tornar-se "[...] musique informelle, isto é, numa música que se desfizesse de todas as formas que lhe fossem exteriores, abstratas, rigidamente contrapostas, e que, completamente livre do que lhe fosse heteronomicamente imposto e lhe fosse estranho, se constituísse, porém, de uma forma objetivamente necessária" (ADORNO, 1994, p. 272). ${ }^{3}$ A vanguarda musical do pós-guerra traduziu-se, pois, enquanto atitude estética, em um amplo movimento de emancipação da poética musical em relação a todo o tipo de heteronomias, fossem elas formas de subordinação a outro

2 Acerca deste conceito adorniano de arte, ver Carvalho, 1999, p. 239-240, p. 286.

3 Na interpretação de Mário Vieira de Carvalho (1999, p. 287-289), o conceito de musique informelle aproxima-se da ideia de autorreferencialidade da obra musical. A expressão Vers une musique informelle, cunhada por Adorno, em francês, evoca a atitude de Guillaume Apollinaire (1880-19/8), no seu manifesto futurista. 
sistema simbólico - por exemplo, religioso - ou atualizaçóes de normatividades transmitidas.

A hermenêutica adorniana inscreve a vanguarda musical do pós-guerra na narrativa moderna da emancipaçáo. Nesta, como em outras propostas teóricas, não encontramos, no entanto, uma via de compreensão para as produções culturais que não estão vinculadas à celebração desta autonomia, nem respostas para a indagação acerca do que, relativamente à antiga aliança religião-estética, persiste ou se transforma. Vale a pena recordar aquilo que, neste campo, observou Michel de Certeau nos seus estudos sobre as metamorfoses do crer nas sociedades ocidentais, essas sociedades que fizeram a experiência de fragmentação do cristianismo enquanto corpo social, a desagregação social do "cristianismo objetivo". Certeau procurou compreender esse fim da articulaçáo estrutural entre a experiência pessoal do crente e a experiência social da comunidade através da Igreja enquanto "corpo de sentido" (CERTEAU, 1974, p. 13). A consequência dessa desarticulação é a disseminação do religioso:

As convicções amolecem, perdem os seus contornos, e acabam por se encontrar na linguagem comum de um exotismo mental, numa koinê da ficção: as convicções acumulam-se naquela região em que se diz aquilo que já não se faz, região onde se teatralizam as questões que já se não conseguem pensar, e onde se mesclam "necessidades" várias, ainda irredutíveis, mas desprovidas de representações crediveis. (CERTEAU, 1987, p. 183).

Nessas deslocações do crer, e nos modos de produção dos avatares da crença, desenham-se figuras táticas que recorrem à religiosidade enquanto reserva de fragmentos disponível para as agências de marketing, os empreendimentos estéticos, e os reinventores dos valores da civilidade. Os utilizadores dessas relíquias não são já fiéis crentes, são gestores e consumidores, são criativos, que utilizam os escombros de um naufrágio em função de determinadas necessidades, em função de certos programas, dentro dos quais as Igrejas podem ser "museus de crenças sem crentes" (CERTEAU, 1990, p. 264). Nesse contexto, o cristianismo tornar-se um arquivo de vocabulários, um tesouro de símbolos, um fornecedor de signos e práticas reutilizáveis no quadro de um trabalho de bricolagem incontrolável.

Este é o contexto em que a elaboração simbólica do sagrado se pode emancipar dos objetos convencionalmente reconhecidos como religiosos, e 
estes mesmos podem ser matéria para novas recomposiçôes em um regime de paródia simbólica em que os mitemas e os ritemas não podem ser já explicados pela lógica do credo que os organizava, ou pelas práticas reguladas que os atualizavam ${ }^{4}$ A proposta interpretativa de Michel de Certeau desdobra-se em três vias. Em primeiro lugar, "a folclorização do cristianismo objetivo" (CERTEAU, 1974, p. 9-13). Algumas décadas atrás ainda a crença cristá estava solidamente ancorada em grupos e comportamentos específicos. Não havia lugar para a fluidez dos contornos. Ou se aderia a uma linguagem ou se entrava para as fileiras dos que a combatiam. Em uma segunda via, Michel de Certeau considera as dinâmicas de "esteticização do religioso" (CERTEAU, 1974, p. 18-20). O corpo de escritos e ritos cristãos é utilizado como um conjunto de belas artes, servindo aos interesses da criação estética: desde as poéticas mais secretas às composiçóes teatrais e musicais, passando pela reinvenção das práticas dos espaços e das arquiteturas cristãs. Por fim, é necessário ter em conta os processos de erosão das fronteiras dos sistemas simbólicos. Este tópico decorre daquilo que Certeau percebeu como uma extensa crise da credibilidade das instituições (CERTEAU, 1974, p. 27-31). Desde há, pelo menos, três séculos, o estatuto de administração da verdade, pretendido pelas instituiçóes eclesiais, foi sofrendo uma profunda crise. Esta dissonância deixou mesmo de necessitar de assumir formas contestatárias. Multiplicam-se, pois, os "cristãos sem Igreja”, sem que isso se traduza na constituição de grupos periféricos à maneira do séc. XVII - que renunciam à mediação eclesial, em nome de uma religião mais espiritualizada. Desprovidos das antigas garantias - políticas, cosmológicas e outras - os sistemas simbólicos veem-se desprotegidos das fronteiras que os defendiam, ficando o seu patrimônio simbólico à mercê de reapropriaçóes diversas em contextos culturais múltiplos.

Embora próxima, a metáfora do "fragmento" usada por Michel de Certeau - figura do estilhaçamento de uma memória autorizada -, distingue-se da

4 "Paródia" não tem aqui o sentido de comentário irónico. Tem o sentido de contrafactura, tal como no século XVI era usado para caracterizar processos de composição que partiam de um modelo preexistente, modelo que por vezes nada tinha que ver com o caráter ou a função da obra final. Estas apropriações podiam afetar o texto (um texto antigo com uma nova música) ou o texto e a música (adaptação e desenvolvimento de um elemento musical com um texto novo). Veja-se, por exemplo, a utilização da chanson "Malheur me bat" de Ockghem na Missa de Josquin des Prez que tomou o mesmo nome. Na historiografia essa missa é designada, por isso, de "missa de paródia" ou "de imitação", e no seu tempo seria identificada como "missa de imitação (paródia) de "Malheur me bat". Paródia não tem, aqui, um sentido pejorativo, identifica apenas um processo de composição musical (Teixeira; Delgado, 2003). 
metáfora do "resto", proposta por Marcel Gauchet. Reinscrevendo a questão da secularizaçáo na tese weberiana do "desencantamento do mundo", Marcel Gauchet caracterizou o cristianismo como a religiáo da "saída da religião". Uma particular concepção de transcendência de Deus e de autonomia do mundo, quanto ao seu fundamento, terão favorecido, na ótica de Gauchet, uma trajetória cultural de erosão do religioso vivido enquanto experiência de desapossamento do fundamento da existência. A tese da secularização de Gauchet estrutura-se a partir do pressuposto da inexorável erosão da função social da religião:

A eliminação da função social fundamental do religioso não deveria, normalmente, acabar por levar consigo uma perda ou uma erosão inexorável, mesmo que muito lenta, da própria possibilidade de uma crença? Poderíamos ser tentados a pensá-lo. A não ser que nos deparemos com outro problema, que complica manifestamente os dados: a função subjetiva que a experiência religiosa conserva - ou adquire - quando se apaga a sua função social. (GAUCHET, 1985, p. 236).

$\mathrm{Na}$ sua conceitualidade própria, Gauchet vaticina que idade da religião como estrutura encontrou o seu termo. Mas seria ingênuo pensar que o mesmo se poderia afirmar da religião como cultura. Gauchet (1985, p. 133s) fala de um "resto" de "experiências singulares e sistemas de convicçôes" enraizado no núcleo último de religiosidade, constituindo-se em "resto antropológico irredutível". A sua leitura acaba por se centrar na afirmação de que a experiência subjetiva de tipo religioso não tem qualquer ligação necessária a um conteúdo. O "estrato subjetivo ineliminável do fenômeno religioso" é o fundamento da experiência religiosa e é anterior a toda e qualquer formulação explícita de religião. Assim, Gauchet tanto afirma o caráter irredutível da experiência religiosa como nega que, a partir desta irredutibilidade, se possa afirmar o caráter necessário de qualquer religiáo. Gauchet separa a experiência, que qualifica de religiosa, da esfera da religiáo. É que a experiência religiosa subjetiva, para que remetem os sistemas religiosos constituídos, pode funcionar por si mesma. Não tem necessidade de se projetar em representaçôes fixas, articuladas em um corpo doutrinal e social. Pode atualizar-se em um lugar-outro, diferente daquele que havia sido o seu território predileto (GAUCHET, 1985, p. III e 292s).

Gauchet (1985, p. 293-303) procurou determinar a estrutura teórica deste "substrato antropológico" identificando os "restos de religião". Um desses 
restos é, para o autor, a experiência estética. Ela diz respeito à forma como se recebe a aparência das coisas, à organização imaginária da nossa captação do mundo; nela está em causa a nossa faculdade de imaginação e não a nossa faculdade de intelecção (GAUCHET, 1985, p. 296). A experiência estética surge identificada com a experiência do sagrado, a irrupção do "totalmente-outro" na familiaridade das coisas (GAUCHET, 1985, p. 297)5. Experiência da diferença e da ruptura, a percepção estética apresenta o mundo enquanto abertura a um mistério que náo se conhece, oferecendo-se como mediação do sagrado:

O sagrado é, especificamente, a presença da ausência [...], a manifestação sensível e tangível do que normalmente está fora dos sentidos e da captação humana. E a arte, no sentido em que nós modernos a compreendemos, é a continuação do sagrado por outros meios. Quando os deuses desertam do mundo, quando cessam de vir e aí significar a sua alteridade, é o próprio mundo que se nos afigura outro, revelando uma profundidade imaginária que se torna objeto de uma procura especial, dotada de fim em si mesma, reenviando apenas para si própria. Assim, a apreensão imaginária do real, que constituía o suporte antropológico da atividade religiosa, começa a funcionar por si própria independentemente dos antigos conteúdos que a canalizavam. (GAUCHET, 1985, p. 297).

A diferença, a alteridade, a profundidade, não podem, pois, encontrar-se nos limites do mundo, pois este, desde o "fim da religião", não sinaliza nada fora de si mesmo. Na perspectiva de Gauchet, somente a experiência estética, que antes era um dos suportes do sagrado - e se converteu, na modernidade, em arte pela arte -, pode romper com a linearidade do quotidiano, manifestar a presença da ausência. ${ }^{6}$

\section{Amnésia e Anamnese}

É bem conhecida a tese de Norbert Elias (1993) sobre Mozart - uma das mais influentes tentativas de construção de uma sociologia da genialidade musical. Elias vê no percurso de Mozart, em particular no seu itinerário

5 Encontramos alguns ecos da noção de "sagrado" de Rudolf Otto (Das Heilige, 1917).

6 Note-se que o uso do campo semântico "criação", para qualificar a atividade artística, transporta claramente uma herança biblica e cristã, aquela que, para Gauchet, está na origem da "saída da religião". As conotações podem ser diversas: atividade artística enquanto produtora de novos objetos e ideias; a relação contemplativa com o objeto; a articulação entre trabalho (transformação do mundo) e jubilação (a celebração da vida); as correlações entre técnica e estética; para além da disseminação da ideia de experiência artística como forma de transcendência. 
de emancipação em relação à corte e ao poder eclesiástico, a emergência do indivíduo-compositor como ator social, que se afirma fora dos quadros institucionais que regulavam o seu ofício - o "profissional independente". ${ }^{7}$ Isso se reflete na própria música, na medida em que os novos contextos sociais vão permitir a afirmação do compositor, na sua individualidade, de uma forma que não conhecíamos antes. As formas musicais emancipam-se de maneira mais vincada da sintaxe ritual, religiosa ou política, que lhes deu origem. Nessa linha de análise a Missa Solemnis de Beethoven surge, com frequência, como um protótipo. Aí o texto do comum da missa, segundo o ordo romano, é o suporte de um programa composicional que é inverossímil na própria cena ritual - a escala da obra musical não se compatibiliza com o tempo-duraçáo ritual (DRABKIN, 1981).

Concentrando o seu olhar nesta via de mudança cultural, Hans Küng (2008), em um ensaio teológico sobre música e religião em Mozart, Wagner e Bruckner, apresenta a tese de uma radical incompatibilidade entre a modernidade musical e a tradição de música sacra, historicamente construída na Europa. Nesta contraposição, Hans Küng vê, de um lado, uma tradição musical que procura narrar uma tradição religiosa partilhada, do outro, a afirmação de uma irredutível subjetividade, onde a religião se torna religiosidade (ou segundo códigos mais usuais, hoje, "espiritualidade”). Hans Küng faz subsistir o modelo weberiano da tensão, a partir da incomensurabilidade que justapóe a música como prática de uma narrativa partilhada (comunidade) e como recurso de afirmação de si (indivíduo).

Esta observação de Hans Küng parece não ser suficiente para uma compreensão da pluriformidade dos itinerários de autonomização dos criadores. De fato, o estatuto de artista sofreu, na modernidade histórica, amplas remodelaçóes. Passou-se do artista-artesão ao artista-profissional que procura autoproduzir-se (ROBINEAU, 2000, p. 87). No modelo artista-artesão, o papel do criador joga-se na missáo de representar a narrativa religiosa. $\mathrm{O}$ artista-profissional é um ator social com margens próprias de autonomia. Quando, a

7 Para uma sociologia da profissão de artista, na perspectiva que interessa a este artigo, um clássico de referência (HEINICH, 1993). Importa confrontar esta via de análise com a tese de Bourdieu. Para o sociólogo, a emergência de um discurso libertário no campo da produção artística, sob o signo da autonomia, não é mais do que uma resposta adaptativa a um mundo que se está a transformar e onde as antigas tutelas estão, também, a perder a sua capacidade de exercício do mecenato (BOURDIEU, 1969, p. 161-177). 
partir desse lugar exterior de autonomia, o artista se apropria de algo, no vasto arquivo do sagrado, pode dizer-se que há uma lógica de (re)utilização - ou seja, o reportório que resulta da atividade de simbolizaçáo do sagrado é posto ao serviço de uma produção artística. $\mathrm{O}$ que pode ser intrigante é o fato de se procurar essa (re)utilização dos materiais do sagrado para atribuir valor à obra artística e solicitar uma atitude diferente do público.

Uma parte da análise social tende a privilegiar, neste contexto, não o religioso objetivado institucionalmente, mas o religioso fluído, implícito, ou cristalizado em substitutos funcionais. Em um célebre artigo de 1968, o antropólogo Roger Bastide lembrava: o sagrado não morre, desloca-se (BASTIDE, 1968). Esta perspectiva de Roger Bastide sobre as deslocaçôes do sagrado conheceu uma importante recepção nos estudos religiológicos do Quebeque das décadas de 80 e de 90, no século passado. Robert Tessier mostrou como os discursos, em diversos domínios socais, (re)utilizam o vocabulário religioso para propor uma nova ética ou novas respostas para problemas sociais. Na sua hermenêutica - onde se pode descobrir algo da herança durkheimiana, o sagrado define-se como função semântica que gere a tensão social dos grupos humanos, tecendo os laços de solidariedade e fabricando as representações simbólicas necessárias à construção das identidades coletivas (TESSIER, 1994, p. 12). Neste modelo de análise, as dificuldades de reconstituição das configuraçóes do sagrado herdado conduzem a novas estratégias de sacralização. Os artistas, a partir do modelo profissional - ou seja, para além do jogo, o trabalho - participam da reflexão e construçáo dos novos tempos e espaços do sagrado. Os veículos de difusão da arte abrem o espaço da criação ao da exposição, solicitando a contemplação (ROBINEAU, 2000, p. 90). Os criadores de arte contemporânea podem, agora, manusear os antigos suportes simbólicos da religiáo para legitimar a sua própria proposta de valor.

A observação das relações entre a produção de obras musicais na geração do pós-guerra e as narrativas e os mitemas religiosos, na perspectiva de Föllmi, acentuam uma direção, já anteriormente documentada: a afirmação das dimensôes subjetivas da criação musical faz-se em um itinerário de emancipação da ritualidade litúrgica (FÖLLMI, 2012, p. 278). ${ }^{8} \mathrm{Na}$ medida em que

8 Tenha-se presente que, segundo uma das teses mais influentes nos anos 1980, a de Habermas, a prática religiosa, para além da sua orientação ética, enquanto ritual tenderia a tornar-se obsoleta. O simbolismo religioso 
a liturgia, nos universos institucionais cristãos mais formalizados, assume um caráter público, a gramática institucional e a sintaxe comunitária têm uma clara proeminência, diminuindo o espaço da liberdade criativa individual. A persistência do religioso acontece à custa de uma poiesis de individualização, em uma relação de divergência com a cena ritual comunitária - o que não quer dizer que a estética e a política do ritual não possam recompor-se, em um contexto novo de aproximação da obra musical à participação dos públicos, como adiante se mostrará. Em termos gerais, pode afirmar-se que o indivíduo criador ocupa o espaço da instituição mediadora. Mas isso não inviabiliza estratégias que visam à ficção de uma comunidade.

Como já se sublinhou, esta paisagem social não é homogênea. É necessário encontrar uma hermenêutica que explique quer a persistência da referencialidade religiosa na criação musical de tradição europeia, tanto na primeira como na segunda metade do século XX, quer o fato inédito de descobrirmos compositores em cujo catálogo não encontramos o rasto de qualquer explicitação de referências às narrativas bíblicas ou aos ritos cristãos, recurso essencial para a grande tradição de música sacra de matriz europeia. A título de exemplo, no contexto do modernismo musical da primeira metade do século XX, a última obra que Arnold Schönberg escreveu, em 1950, tem o título Moderne Psalmen. ${ }^{9}$ Todavia, é necessário assinalar também que, de forma inédita, conhecemos compositores em cujo arquivo não encontramos qualquer relevância dada à tradição europeia de música sacra, como em Webern. ${ }^{10}$

A hipótese, que neste percurso de investigação se persegue, aponta para uma correlação entre os usos do religioso e o lugar da memória nos processos

é interpretado por Habermas como raiz "pré-linguística" do agir comunicativo (os símbolos sagrados arcaicos exprimem um consenso normativo tradicional prolongado e renovado na prática ritual). As funções ligadas à reprodução simbólica do mundo vivido - reprodução cultural (cultura), integração social (sociedade) $e$ socialização dos indivíduos (personalidade) -, abandonaram progressivamente o domínio sacral em direção às estruturas profanas da comunicação pela linguagem. Esta "verbalização", ou este "pôr-em-linguagem" do sagrado traduz um processo segundo o qual a autoridade da fé é substituida pela autoridade do consenso racional visado pela comunicação, ou seja, um consenso resultante da discussão livre e argumentada entre sujeitos capazes de falar e de agir (HABERMAS, 1981, p. II8, p. 292, p. 487).

9 Moderner Psalm für Sprecher, Gemischten Chor und Orchester, Op. 50C (1950).

10 No entanto, o compositor britânico John Tavener - um dos mais reconhecidos no universo da música ortodoxa contemporânea - considera a música de Webern como uma das mais espirituais. A sua concisão e a sua abstração são qualidades tomadas como indícios de sublimidade espiritual. A narrativa e rito dispensam-se na criação simbólica de um espaço interior, que John Tavener lê como rasto de uma atitude mística. Isso mesmo ele explica em uma entrevista dada à BBC, disponivel em: <http://www.bbc.co.uk/programmes/p04pddst>. 
composicionais. A memória é, na expressão de Jean-Marc Chouvel (2003, p. 47), a possibilidade de o tempo passar da pura fluidez à forma. A partir deste princípio orientador, podemos encontrar certo mapeamento dos processos composicionais. Observe-se que em boa parte da música criada no século XX se adotou a atitude de reivindicação de uma teoria autónoma para cada obra. Aqui se podem enraizar uma parte dos problemas vividos pelos públicos. É que a nossa capacidade de escuta não parece ter uma versatilidade tão radical. Em qualquer dos casos, uma obra que se escreve no tempo não pode deixar de solicitar uma relação com a memória (CHOUVEL, 2003, p. 48-51). Estudar as obras musicais a partir das suas relaçôes com a memória pode revelar-se eficaz, quando perseguimos nelas os matizes da sua referencialidade religiosa. A abordagem da religiáo como modalidade de crença que institui uma tradição põe em evidência um fato frequentemente observado: que não há crença religiosa que não se refira a um material simbólico recebido, a uma herança legada, a uma memória que solidariza o passado e o presente, contribuindo, assim, para diminuir os riscos do transitório ou da mudança agressiva. Nesse sentido, a crença religiosa cria um espaço de comunicação, onde o crente é chamado a responder a uma precedência feita de imagens e narrativas. A dinâmica religiosa declina-se genealogicamente, enquanto relação com uma memória fundadora, transmissão recitada e praticada. Ser religioso é, deste ponto de vista, saber-se gerado - ou, nas sociedades mais individualizadas, querer sentir-se gerado (TEIXEIRA, 2015, p. 37-58). A concentraçáo metódica nesta perspectiva pode contribuir para a construção de um modelo compreensivo dos usos da memória religiosa nas práticas composicionais contemporâneas.

Neste contexto de indagação, é curioso observar que o percurso de Stravinsky criou alguns problemas às vanguardas do pós-guerra. As metamorfoses do seu trabalho composicional ancoraram-se persistentemente em uma relação com a memória da criação musical europeia. Nas interpretações mais brandas, o compositor não era visto como tradicionalista porque não canonizava nenhuma tradição. Ou seja, a sua relação com a memória declinava-se em um jogo em que ele próprio era protagonista - escolhia a tradição. Ora "escolher" a tradição não é, nesta perspectiva, um gesto tradicional."

II Esta era a tese de Schloezer e Sciabine, em 1959. 
Na modernidade musical, depois de 1945, Makis Solomos sublinha a preponderância, em face à memória sócio-histórica, de uma vontade de amnésia. Xenakis é tomado como exemplo de uma total ascese da memória e Boulez como representante de uma amnésia voluntária parcial (SOLOMOS, 2003, p. 239-241). Xenakis transporta biograficamente a figura do migrante oriundo de uma região habitada pelos traumas do século XX, forçado a um processo de ampla reconstrução da identidade. Os cenários concernentes ao lugar dos materiais da tradição no processo composicional implicaram um confronto com a tradição "popular" grega (que ele qualifica de demótica), com o jazz, com a música europeia tradicional, com o dodecafonismo e com a eletrônica. A sua resposta foi radical. Nas obras Metastasis e Le Sacrifice deparamo-nos com uma vontade de renúncia a qualquer tradição. Trata-se de uma modernidade ex nihilo, com a ambição de, por via de um grau elevado de abstração, se chegar a um novo universalismo. Esse vazio de memória é compreendido como espaço de liberdade, onde é possível reconstruir todas as referências (XENAKIS, 1963, p. 185).

Em Jalons (pour un décennie), de 1989, Boulez expóe este problema de forma dilemática. Estamos em um período em que as tendências vanguardistas sofreram já a erosão das diferentes ondas da pós-modernidade - seguindo aqui uma categorizaçáo muito divulgada (LYOTARD, 1996). Boulez observa que se vive um tempo cada vez mais carregado de memória, tornando-se urgente o esquecimento. A sua posição transcreve-se em um jogo difícil de equilíbrios. Ele opóe-se a dois extremos: os que vivem da exaltação dos arquivos da música do passado e os atletas da tabua rasa, para quem o presente não tem origem. Para Boulez, não há tradição, mas apenas uma cadeia de indivíduos que se serviram reciprocamente de modelos e ferramentas (BOULEZ, 1989, p. 437441). Enfatiza-se, assim, a desautorização da tradição ou, de outro modo, o caráter não necessário da tradição.

Em ooutros universos, pode encontrar-se uma lógica diversa, que Makis Solomos (2003, p. 241-244) carateriza a partir da categoria anamnese. John Adams, Arvo Pärt, Penderecki ou Wolfgang Rihm, podem exemplificar, na sua heterogeneidade, essa vontade de memória. Tomando o exemplo de John Adams, a sua passagem do minimalismo americano dos anos 1970 para modelos mais híbridos, visa a perpetuar o que apelida de leis musicais universais: 
a periodicidade, a pulsação e a tonalidade (ADAMS, 2009). No caso de Arvo Pärt, no período de obras como Tabula rasa (1977), o desejo de visitar certa representação da música medieval é muito claro, identificando-se com a figura do compositor anônimo - como que um exercício de ascese autoral. No quadro do atual funcionamento do campo musical, o anonimato autoral é uma ficção simbólica, mas não deixa de produzir sentidos. A densificação da presença explícita dos arquivos da música do passado é particularmente visível na música que é etiquetada de "sacra". A etiqueta "música sacra”, porque remete para formas amplamente inscritas na história da música europeia, pode captar a atenção de um público mais vasto. Esse aspeto pode funcionar como um facilitador de leitura, para novas linguagens (ROBINEAU, 2000, p. 86). $\mathrm{O}$ apelo à memória ritual, ou a imaginários religiosos recebidos, pode oferecer um contexto de mediação para as novas linguagens. Sob o signo da amnésia, como se referiu, outros compositores recusaram a reutilização dessa memória em nome de uma ruptura ou como expressão de uma radical autonomia.

A terceira constelação proposta por Makis Solomos (2003, p 244-246) diz já respeito aos efeitos da mundialização sobre a ideia de tradição. Neste caso, não se trata de amnésia, nem de anamnese no sentido anteriormente referido. Trata-se de integrar no processo de composição a memória das culturas. Este sentido de etnicização esteve, de maneiras diversas, presente em parte do corpo das criaçóes de compositores tão diferentes quanto Bartók e Berio. No exemplo tomado por Makis Solomos (2003, p 244-246), está mais patente o desejo de renovar as estruturas composicionais a partir de processos descobertos em um pluriverso de referências culturais. Obras como Drumming (1970-71), Music for Eigtheen Musicians (1976) ou Tehillim (1981) de Steve Reich podem documentar esta atitude. A expressão "influências extraeuropeias" pode não ser muito ajustada. Reich não vai à procura do exótico. Não é a estranheza do som que ele procura, mas a descoberta de processos estruturais. E, neste contexto, todas as tradiçóes estão disponíveis: a tradição europeia de 1200 a 1750, a música para gamelão de Java e do Bali, a música que resta da África ocidental, o jazz americano entre 1950 e 1965 , a modernidade da primeira metade do século XX ou a cantilação tradicional das Escrituras hebraicas (REICH, 2002). As estruturas que aí descobre estabelecem uma relação construída com o acervo organológico da música de matriz europeia, prescindindo da necessidade de recorrer, como ficção dessa 
mundialização, a instrumentos extraeuropeus. Steve Reich trabalha no quadro de certo universalismo abstrato, onde as culturas são um vasto stock disponível, sem que nenhuma tenha uma autoridade particular ou exija a sua reprodução. São fragmentos heteróclitos disponíveis, que somente no próprio programa composicional ganham sentido.

Estamos no cerne das dinâmicas sociais definidoras das múltiplas modernidades (EISENSTADT, 2000), testemunhando a emergência do "tempo do globo" (SLOTERDIJK, 2005). Muitos dos intérpretes da nossa contemporaneidade sublinham a centralidade desta dinâmica social. Nestor Canclini (2004) usa a expressão "culturas de fronteira" e Arjun Appadurai (1996) propóe o neologismo ethnoscape para falar de uma paisagem humana marcada por mobilidades de escalas diversas. Um dos mais importantes representantes da chamada história cultural, Peter Burke (1993), procurou mostrar que o hibridismo cultural é, na sua pluriformidade, um dos fenômenos mais identificadores da modernidade histórica. Este é o terreno da metáfora lançada por Claude Lévi-Strauss (1962) - a metáfora da bricolagem, usada para traduzir a forma como a imaginação mítica explora o jogo das recomposiçôes possíveis do stock de materiais fragmentados, heterogêneos e heteróclitos assimilados por via da tradição, da importaçáo, ou do desvio. Neste quadro social, os compositores que integram no seu processo criativo as práticas de transumância simbólica, criando novas possibilidades de contato entre fragmentos culturais diversos - de algum modo, assumindo a literalidade do seu nome de ofício - são compositores entre mundos. $\mathrm{O}$ intervalo, a diáspora, o trânsito, a fronteira, os lugares intersticiais constituem o seu habitat criativo. Esta via está particularmente representada em muitas das atuais tendências interpretativas no universo da chamada "música antiga". O efeito de crioulização, neste contexto, tornou-se um recurso muito disseminado (TEIXEIRA, 2016).

\section{Tensão e desvio}

Como se tem vindo a observar, nas sociedades marcadas pela memória religiosa cristá, o sagrado e a arte conheceram metamorfoses que se podem correlacionar. A tensão, no modelo weberiano, pode concretizar-se nos itinerários de autonomização artística, já referidos. Mas pode também assumir a configuração do conflito cultural - que noutros momentos históricos tomaria corpo 
na figura de blasfêmia. Nas sociedades que fizeram a experiência histórica da secularização, na sua diversidade, a esfera da significação e prática religiosas, ao relativizar-se, deixa de poder instituir-se como centro organizador da percepção dos limites. Fica, assim, reduzida a possibilidade de identificação social do "blasfemo" ou da "blasfêmia", uma vez que as operaçóes que permitiam a identificação religiosa das fronteiras últimas não têm cátedra. Não é por acaso que as atuais tensóes entre a liberdade de expressão e o direito dos grupos religiosos a verem respeitado o seu patrimônio acabam por se transferir para esfera da argumentação ética e axiológica, onde, apesar das lutas ideológicas, se podem construir alguns consensos (TEIXEIRA, 2008/2009).

Nesse novo contexto, o sacrilégio não consiste já, tipicamente, em um ato como o de profanação de um lugar sagrado. Em certa perspectiva, o sacrilégio tornou-se a missão da arte que se autorrepresenta como contemporânea. Se nos servirmos da conceitualidade de Marcel Duchamp (1994), a atitude estética própria desta arte passaria pelo "desvio" (détournement). Nesse horizonte explicativo, a obra de arte consiste nesse colocar algo (artefato, ideia, ato, dito, escrito) fora do seu contexto, em um lugar exterior à sua legibilidade recebida. Esse "desvio" visa ao investimento em um outro sentido ou, no mínimo, "dar que pensar" (o mesmo é dizer "dar que falar"). Nesse contexto, a arte contemporânea faz do que, em um quadro social diverso, seria blasfêmia, a nova moral crítica, o novo sagrado. Verdadeira blasfêmia seria agora a censura desse poder "desviante" da arte e a defesa desta "transgressão" torna-se um serviço público - até porque uma parte importante da produção artística nas sociedades europeias depende, de forma relevante, do Estado (KERROS, 2012, p. 21). Nesta ordem de análise, as disputas entre grupos religiosos e o campo da arte contemporânea estariam próximas da figura da "guerra de religião". Não será por acaso que, nos EUA, estas disputas públicas foram designadas de cultural wars (HARTMAN, 2015).

Observe-se, no entanto, que certas criaçóes artísticas, sobre as quais se abate a querela da blasfêmia, podem ser lidas por certas sensibilidades como obras que póem em evidência aspetos tidos por essenciais no cristianismo, mas toldados pelo peso das incorporaçóes históricas. Paradoxalmente, o que uns interpretam com ofensa, outros percebem como reabilitação - neste caso, o mecanismo do desvio produz um efeito de desocultação. $\mathrm{O}$ argumento 
essencial diz respeito ao fato de que elas não procuram a transgressão como um fim, mas como um meio eficaz para criticar o mainstream, que inclui tanto ideologias como práticas religiosas. A obra Piss Christ (1987) dá testemunho destas ambiguidades. Andres Serrano fotografou um crucifixo banal, sem aparente valor artístico, imerso na sua própria urina - a obra faz parte da série Immersion, ciclo em que vários objetos sofrem os efeitos da imersão em diversos fluídos (SHINE, 2015). A obra tem somado querelas. Quando exposta em Avignon, em 2011, a obra chegou a ser vandalizada. ${ }^{12}$ Um dos casos mais comentados, na esfera católica europeia, diz respeito ao próprio diálogo que o bispo de Poitiers, Albert Rouet, estabeleceu com um conjunto de obras e artistas selecionados por Gilbert Brownstone. Entre eles, encontra-se o fotógrafo Andres Serrano. O comentário de Albert Rouet confronta o cerne da mensagem cristã - a "carne de Deus" como "carne do diálogo" - com um conjunto de obras que vulgarmente transportariam a etiqueta da provocação. $\mathrm{O}$ bispo tende a valorizar a capacidade que estas obras têm de colocar os seus interlocutores perante o mais decisivo da vida humana, partilhando, nessa qualidade, o cerne das narrativas da encarnação e da páscoa cristãs: "Eu chamo obra de arte àquela que me fende, que me atravessa, para que aceite ir na direção do mistério que me habita" (BROWNSTONE; ROUET, 2002, p. 107).

Igualmente polêmica, a obra de Romeo Castelluci, Sul Concetto di Volto nel Figlio di Dio (2010), documenta a mesma ambivalência. A obra dramatúrgica desdobra-se em três sequências independentes que, segundo o autor, visam a materializar o momento em que Cristo entra na carne humana. Ao encenador italiano interessa compreender o abandono da condição divina. Diálise, incontinência, matéria fecal, apedrejamento do rosto de Cristo - na reprodução da obra do pintor Antonello Da Messina, Salvatore Mundi (1465) - dão corpo a uma reflexão escatológica que, em algumas leituras, foi classificada de cristianofóbica. Em uma entrevista ao jornal Le Monde, em 27 de outubro de 2011, o encenador declarava: "Eu faço um teatro de questionamento, de inquietude, que joga com a ambiguidade [...]. A arte repousa inteiramente sobre a condição de levantar problemas, caso contrário é puramente

120 rasto das polêmicas está patente nos arquivos da comunicação social. Por exemplo: <https://www. theguardian.com/world/201//apr//8/andres-serrano-piss-christ-destroyed-christian-protesters>; <http://www.lemonde.fr/culture/article/201//04/18/la-destruction-de-piss-christ-uvre-impie_/509/85_3246.html>. 
decorativa [...]. Atualmente, a religiáo perdeu a sua capacidade de colocar perguntas e a arte tomou o seu lugar" (LE MONDE, 2011). ${ }^{13}$

A figura dessa cultural wars não encontra, no arquivo musical, registos públicos tão evidentes. Elas reproduzem-se mais facilmente na mediasfera das culturas visuais. Este tipo de atitude estética encontra na música recursos talvez mais complexos, mais abstratos e, por isso, não são documentadas, com tanta frequência, querelas públicas. Mas a estética do détournement encontra paralelos na criação musical de alguns dos compositores mais marcantes da segunda metade do século XX. A obra de Mauricio Kagel (1931-2008) pode apresentar-se, em alguns dos seus registos, como um importante paralelo. Retêm-se aqui, em particular, o alcance de uma obra: Sankt-Bach-Passion (PETERS, 1985). A obra nasceu de uma encomenda de 1979, para os Berliner Festwochen, começou a ser realizada em 1981 e foi estreada no dia 9 de setembro de 1985. Trata-se de uma Paixão quanto à sua arquitetura — corais, recitativos, árias etc. Mas não é uma narrativa da Paixão de Jesus Cristo segundo um dos evangelistas ou outra fonte. É da Paixão de Bach que se trata: ${ }^{14} H a ́$ já algum tempo que me ocupo dele [Bach] de maneira intensiva, o ponto culminante foi o Chorbuch (1978). Até hoje, a quantidade de emoção contida num simples coral protestante de Bach permaneceu um mistério para mim. Em 1975 ou 1976, comecei a acalentar a ideia de realizar um projeto acerca da pessoa de Bach".

Se a biografia de Bach invade a narrativa, o mesmo não se pode dizer do seu idioma musical. A obra declina-se nos limites da gramática composicional de Kagel (2002): "Eu comecei por aquilo que não queria e, frequentemente, é aquilo que um compositor rejeita que acaba por estimular a sua imaginação. Por isso, nada de citaçôes de Bach [...]. Queria confrontar-me com o superpai Bach apenas por meio da minha própria música".

13 A obra passou por Portugal sem reações públicas comparáveis às documentadas noutros contextos nacionais: <http://www.teatrosaoluiz.pt/catalogo/detalhes_produto.php?id=59/>; <http://www.teatromunicipaldoporto.pt/PT/programa/romeo-castellucci-it-sobre-o-conceito-do-rosto-do-filho-de-deus-sul-concetto-di-volto-nel-figlio-di-dio/?categoria=teatro>.

<https://www.publico.pt/20 /5/12/I7/culturaipsilon/noticia/previsoes-para-20 / 6-romeo-castellucci-divide-o-rivoli-com-um-espectaculo-de-choque-I7/759I>.

14 As citações de Kagel aqui recolhidas fazem parte de uma entrevista conduzida por Werner Klüppelholz, inserida no booklet que acompanha o respetivo CD (Kagel, 2002). 
Kagel não renuncia, no entanto, às oportunidades que seu idioma serial encontra nos esquemas numerológicos e nas formalizaçóes combinatórias de tecnemas (como aqueles que o próprio lexema B-A-C-H permite), em uma aproximação clara à dimensão mais racionalista da obra de Bach. $\mathrm{O}$ recurso aos mistérios da arte combinatória, neste e noutros itinerários musicais no século XX, permite a superação da arbitrariedade do sistema, problema mais agudo agora que os idiomas musicais não são articuláveis a partir de uma gramática de consensos:

Gostaria de ser um verdadeiro cabalista. Sou-o apenas intuitivamente e em estado bruto, esforçando-me por compreender cada vez melhor a significação escondida dos números e das proporções. O mesmo se pode dizer, sem dúvida, de Bach: ele utilizou uma numerologia que, na sua época, era conhecida na arte da composição, mas que mesmo assim não deixa de fazer pressentir misteriosas relações [...]. Dos números do nome de Johann Sebastian Bach deduzi ritmos que, por seu lado, deram origem a novas estruturas. Vogais, consoantes, número silabas e de palauras, transformei tudo isso em séries de durações, intensidades e alturas, e em proporções formais. (KAGEL, 2002).

Tal como nas Paixóes de Bach, a montagem do texto é essencial na organização da narratividade musical. No caso de Sankt-Bach-Passion, encontramos uma pluralidade de fontes que fazem parte dos Bach-Dokumente. O resultado é uma montagem de elementos textuais heteróclitos que reúnem as necrologias deixadas por Carl Philipp Emanuel Bach e por Johann Friedrich Agricola, bem como fragmentos dos textos das cantatas de Bach, adaptados, recompostos segundo lógicas combinatórias que vão fornecendo a Kagel (2002) o material sintático principal: "Esta obra tem que ver com a categoria de música pura com texto. Como acontece frequentemente em Bach. A música pura não é uma música que evita a palavra, mas uma música em que a palavra se torna música".

A obra narra uma vida marcada por um calvário de sofrimentos, explorando o contraste entre as condiçóes penosas de existência de um cantor que não chegou ao topo das honrarias do seu tempo, mas que produziu uma obra musical capaz de sobreviver a qualquer tempo. Esse material é organizado segundo a arquitetura das Paixôes realizadas por Bach em um jogo de "paródia” que é inverso àquele que o próprio Bach conheceu: a utilização de um tema popular, ou dito profano, em uma composiçáa religiosa. No caso de 
Sankt-Bach-Passion, é uma forma religiosa que é agora objeto da bricolagem "profana”. Kagel "crê" em Bach, no sentido sugerido pela epígrafe da obra:

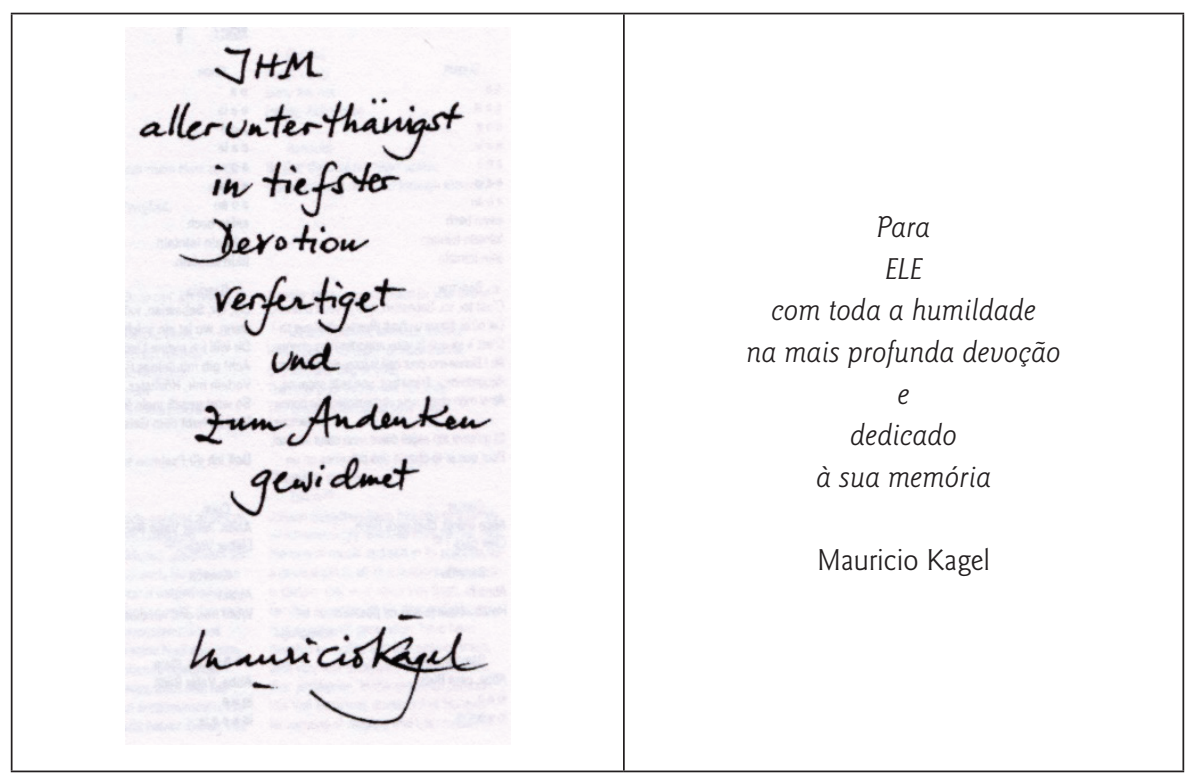

Nesse efeito de substituição da figura de Jesus Cristo, Bach não é, em primeira instância, como o poderia ser para Messiaen, uma figura crística. Ou seja, uma figura, que sob o impulso de uma exegese espiritual se apresentasse como um alter Christus, um ser transparente onde se descobrem os traços da imitação de Cristo - no caso de Olivier Messiaen, por exemplo, a figura de S. Francisco. Na obra de Kagel, trata-se preponderantemente de uma substituição de tipo prometaico. O indivíduo humano toma o lugar de Deus. ${ }^{15}$ Na posteridade de Feuerbach (1973), Deus é aquilo que de mais essencial se pode descobrir na condição humana. Ou em uma linguagem mais próxima de Kagel, a condição humana reflexa. A obra musical tem assim esse efeito de autorrevelação do humano.

15 "Acontece que nem todos os músicos acreditam em Deus, mas todos acreditam em Bach". 


\section{Da tensão à transação}

Diversos estudos têm mostrado que, a apesar da diminuição da capacidade de as Igrejas e outras instituiçôes religiosas tutelarem a economia do sagrado, subsistem indícios de uma procura de satisfação de necessidades de índole espiritual. A capacidade de responder a esta demanda mobiliza muitos atores e instituiçôes, mesmo em um quadro de grande fluidez, com a pretensão de responder a essa procura. A aptidão para responder às exigências próprias deste circuito de necessidades não deixou de ser uma forma possível de construção da credibilidade social. O impacto social dessas iniciativas depende do investimento na reconstruçáo de "espaços de convergência"|6, fazendo dessas experiências, não apenas um contexto de fruição individual, mas uma manifestação social. ${ }^{17}$ Por isso os contextos de posicionamento em face à produção artística são, como se tem vindo a observar, um laboratório eficaz para a compreensão do jogo de tensóes e transações. Nos modelos de investigação mais reproduzidos, o olhar distribui-se recorrentemente por dois cenários: por um lado, o cenário ritual-litúrgico, que continua a mobilizar mediações estéticas; por outro, a esfera pública enquanto lugar de tensôes, muitas vezes resultantes de processos de reutilização da memória religiosa, sob formas novas de contrafactura, desvinculados das autoridades e instituiçóes gerem a transmissão dessa memória. ${ }^{18}$

Mas existem outros cenários, com igual pertinência social, em que atores e instituições religiosas estabelecem relaçôes inéditas com o campo da produção artística. Ademais, participam na própria construção do campo artístico (no sentido boudieusiano), operando uma inclusão da memória religiosa nos processos de transmissão cultural. Roger Caillois (1950) sublinhava que os grupos religiosos tendem a mobilizar-se para tornarem mais acessíveis os seus valores por meio de objetos simbólicos. Mas esse investimento, situado histórica e socialmente, pode corresponder a sentidos diversos. Em certas vias de análise, estas lógicas de ação dão corpo a itinerários de secularização interna. Noutras perspectivas, o apoio das instituiçôes religiosas à criação artística é

16 Retoma-se aqui o conceito de "espaces de rassemblement" proposto por Alberto Melucci (1983).

17 Situa-se, nesta perspectiva, o caso estudado por Anne Robineau (2000): Symphonie du Millénaire, projeto musical criado no Quebeque, com apoio estatal, para celebrar a passagem do milênio.

18 Apenas esta segunda lógica de ação foi objeto de indagação neste artigo. 
interpretado como uma via de adequação às deslocações contemporâneas do sagrado. ${ }^{19}$ Neste contexto, é importante ter em conta os regimes de transação que se estabelecem entre as instituiçóes religiosas e o campo dos produtores artísticos. Por um lado, os universos religiosos fornecem materiais (constelaçōes de narrativas, imagens e formas) inscritos no médio e longo curso das culturas. Isto acontece por via da patrimonialização de signos, narrativas e práticas religiosas, mas também por via de outras formas de transação em que o stock simbólico-religioso fica disponível para as mais variadas recomposiçóes estéticas. Por outro lado, náo se tratando de uma arte de Igreja (como outrora a musica da chiesa), mas da constituição de lugares-fronteira, as Igrejas vêm alargado o seu lugar de inscrição - um espaço de cidadania partilhada -, aberto a novos sentidos de pertinência pública.

$\mathrm{O}$ acesso a estas estratégias diferencia as instituiçóes e grupos religiosos. Na geografia cristá, é possível distinguir as lógicas que privilegiam a dinâmica da conversão individual e aquelas que favorecem estratégias de cristianização por via das mediaçóes culturais. Esta segunda via, não sendo exclusiva, descobre-se mais facilmente em Igrejas que valorizam o seu próprio patrimônio como medium, no sentido de veículo ou de ponte, privilegiando estratégias de inclusividade. A historiografia e sociologia da recepção do II Concílio do Vaticano sublinham a persistência de estratégias de "reconciliação" da Igreja católica romana com os criadores de arte (SAINT-MARTIN, 2012, p. 266-268). Esta instituição conheceu uma transformação, no quadro da qual as iniciativas de diálogo com os não crentes (Pontifício Conselho para o diálogo com os não crentes), foram enquadradas em um modelo orgânico novo, a partir de 1993, passando a integrar Pontifício Conselho para a Cultura, sob a tutela ativa do cardeal Poupard. A partir de 2007, o cardeal Ravasi renovou o protagonismo deste órgão, renovação que podemos documentar em iniciativas como o "Pátio dos Gentios” ou a participação, a partir de 2013, na Bienal de Veneza. É necessário dar atenção também a um documento publicado sob a autoridade de João Paulo II, a "Carta aos artistas", de 1999, bem como o encontro com os artistas na Capela Sistina, em 2009, patrocinado por Bento XVI. ${ }^{20}$

19 Tenha-se em conta as posições clássicas de Isambert (1976) e Prades (1987).

20 Disponivel em: <https://w2.vatican.va/content/john-paul-ii/pt/letters/I999/documents/hf_jp-ii_let_2304 1999_artists.html>; <https://w2.vatican.va/content/benedict-xvi/pt/speeches/2009/november/documents/ hf_ben-xvi_spe_2009II2I_artisti.html>. 
No edifício institucional católico, em Portugal, é possível identificar várias iniciativas que dão testemunho desta lógica de ação. Antes de mais, a valorização, nos órgãos da Conferência Episcopal Portuguesa, do Secretariado Nacional da Pastoral da Cultura. Entre 2003 e 2014, foi seu Diretor, o padre, poeta e teólogo, José Tolentino Mendonça, personalidade amplamente reconhecida nos meios intelectuais portugueses e com alargada inscrição em diversos setores da sociedade, seja pela sua presença em um dos principais semanários da imprensa portuguesa, seja pela presença das suas obras de espiritualidade no grande circuito livreiro. No âmbito deste organismo da Conferência Episcopal Portuguesa, instituiu-se o prémio "Árvore da Vida - Padre Manuel Antunes", bem como a participação, também com um prêmio, no festival de cinema Indie Lisboa. ${ }^{21}$ Estas iniciativas podem, a partir da dinâmica local da Igreja católica romana, integrar-se em projetos culturais de desenvolvimento regional. É o caso do Festival Terras sem Sombra de Música Sacra do Baixo Alentejo, uma iniciativa do Departamento do Patrimônio Histórico e Artístico da Diocese de Beja, com parcerias diversas, cujo conceito de programação reúne a música, o patrimônio cultural e a biodiversidade, com estratégias de captaçáo de públicos que se alargaram ao espaço ibérico (SANTOS, 2011).22

Mas esta aproximação deve ser lida, tendo em conta as reciprocidades que a descrevem. Isabelle Saint-Martin, que tem uma trajetória consolidada de investigação sobre as relaçóes entre as Igrejas e as artes visuais contemporâneas, fala de uma ressurgência de motivos religiosos nos reportórios dos criadores, em um contexto de livre circulação e acesso aos bens artísticos e religiosos (SAINT-MARTIN, 2012, p. 272-274). Como ela observa, não há um sentido único nesta ressurgência: nem o efeito de provocação, nem a lógica confessante descrevem exaustivamente a persistência do religioso na arte contemporânea. Sublinhe-se, mesmo, que, em muitos casos, esse reinvestimento em motivos religiosos é coincidente com uma atitude estética de reinvenção da arte recebida do passado: sob a forma de comentário, desconstruçáo, alusão etc. Por vezes, a atitude estética de revalorização de materiais religiosos não se distingue da própria atitude de valorização da produção artística do passado como suporte de novas formas de comunicação artística - na linha dos processos de anamnese já referidos.

21 Disponivel em: <http://www.snpcultura.org/>.

22 Disponivel em: <http://festivalterrassemsombra.org/>. 
Estes itinerários criativos podem ter um assinalável impacto público. É frequente que as próprias instituições estatais, mesmo nos países com modelos mais rígidos de laicidade, acabem por apoiar arte com referências explicitamente religiosas. Em muitos casos, os resultados estáo longe de qualquer consenso, ou até podem ser lidos como provocação ou blasfêmia (HEARTNEY, 2004). Embora, em muitos casos, não se distingam facilmente as reaçóes a certas formas de reutilização das referências religiosas, da rejeição das próprias linguagens da arte contemporânea (HEINICH, 1998).

No quadro interpretativo que neste artigo se persegue, tanto a criaçáo artística pode ser um lugar de interlocução para as instituições e grupos religiosos - em ordem a tornar pertinente a sua mensagem -, como a memória religiosa, ou especificamente ritual, pode ser um contexto de interface entre o criador e os públicos. Classicamente, a partir da própria etimologia, ars designa a capacidade consciente e intencional de produzir objetos, mas também o conjunto de normas e técnicas que devem ser usadas para se representar o real. Nesta via, a arte compreende-se como técnica de concepção e forma de conhecimento. Para que esta forma de conhecimento se legitime, pode não ser suficiente a individualidade do criador, necessitando de massa crítica. ${ }^{23}$

As estratégias podem passar por modalidades de extensão da ação ao público e pela valorizaçáo dos "lugares-memória", dos "lugares sagrados", enquanto mise-en-scène. São favorecidas, assim, práticas de abolição ou atenuação da distinção clássica entre espetáculo e rito, uma vez que se mitiga a exterioridade do público. Ou seja, todos são praticantes - o que é próprio da ação ritual. As tentativas de abolir a distância entre o espetáculo e o lúdico ou ritual passam pela criação de uma relação, de um jogo de colagem-reunião-montagem de elementos diversos, que são reapropriados, sofrendo ajustes de sentido ou desestabilizando as fronteiras. Como observava Andrée Fortin, “[...] o encontro entre o lúdico e o estético é favorecido pelo fato de, nos dois casos, se ser incluído em qualquer coisa de mais vasto que nos ultrapassa, nos engloba ou fusiona” (FORTIN, 1997, p. 92). Estes contextos de criação não celebram a ruptura com a tradição, à maneira de algumas vanguardas. Trata-se, antes, do gesto utópico que dá a palavra a todos. Nesta utopia da

23 Públicos ou um conjunto de pares, no caso das criações mais concentradas no próprio virtuosismo da técnica e, portanto, menos acessiveis a públicos mais amplos (ROBINEAU, 2000, p. 90-9I). 
participação, os objetos de arte deixam de ser intocáveis para se tornarem manuseáveis - dir-se-ia que esta é, propriamente, a secularização da arte.

No quadro das hipóteses interpretativas que aqui se exploram, é muito útil a revisitação do estudo de caso apresentado por Anne Robineau. A investigação estava focada em um projeto musical que foi apresentado no dia 3 de junho de 2000, no Oratório de São José, em Montreal. Sob a designação de Symphonie du Millénaire, o projeto ganhou a dimensão de um grande acontecimento mobilizador de instituiçóes, compositores, músicos profissionais e amadores e de um vasto público - cuja presença foi integrada na própria concepção performativa da obra. Os contornos do megaevento eram singulares: 19 compositores, 333 músicos-intérpretes, 15 grupos instrumentais, pré-registo dos 15 conjuntos de sinos das igrejas da cidade, 2000 pessoas do público a quem foram entregues pequenos sinos. A relaçáo entre os materiais eletroacústicos e a música produzida no lugar desdobra-se em um comentário ao hino litúrgico Veni cerator (ROBINEAU, 2000, p. 85, 93).

Anne Robineau recolheu os materiais produzidos na mediasfera comunicativa, estudando as categorias de recepção jornalística e os discursos dos protagonistas do evento. A sua atenção centra-se em algumas qualidades que considera cruciais para uma caracterização do acontecimento: a grande reunião, o seu caráter festivo e o desejo de celebrar dois mil anos de cultura partilhada (ROBINEAU, 2000, p. 93-96). Estamos, pois, perante um dispositivo que apela aos efeitos próprios do comportamento festivo, na sua capacidade de diminuir a distância social, promovendo a consciência de uma pertença coletiva - tal como a posteridade durkheimiana o afirmou. Anne Robineau resume assim a sua interpretação das práticas artísticas em questão, comentando que as novas estratégias sociais dos artistas “[...], em particular as que dizem respeito à implicação do público na criação da obra, reunindo-os para além das suas divergências, utilizando os antigos recursos da memória coletiva, conduzindo os artistas a uma reconquista do sagrado de forma pontual e efêmera” (ROBINEAU, 2000, p. 96).

Importa sublinhar que os meios de construção da obra-evento, nesse objetivo de celebrar dois mil anos de cultura comum, recorre ao patrimônio litúrgico e ritual, reutilizando a memória cristã em um contexto que já náo é o da experiência de um cristianismo objetivo, voltando à emblemática 
expressão de Michel de Certeau. A obra-evento é realizada em um contexto de fragmentação do cristianismo enquanto corpo social, retomando a perspectiva de Michel de Certeau (1974, 1987). Nesta situaçáo cultural, a obra-evento Sinfonia do Milênio encontra-se marcada por uma lógica de reutilização que apela a um jogo diferente com a memória instituída.

A antropologia do quotidiano de Michel de Certeau (1990) pode informar uma perspectiva acerca destas lógicas de reutilização. Na sua proposta, a cultura do quotidiano é marcada por duas dinâmicas: a dos produtores e a dos consumidores. Os produtores têm o poder estratégico - o controle dos meios de produção. $\mathrm{O}$ regime de ação dos consumidores define-se por meio de operações táticas. $\mathrm{Na}$ esteira da antropologia das práticas culturais de Michel de Certeau, a investigação descobre um renovado interesse pelas combinatórias de operaçóes que ultrapassam aqueles modelos que faziam dos usagers simples consumidores passivos e dominados. Essa poética do quotidiano, de que falava Certeau, encontra-se disfarçada - talvez como as técnicas de camuflagem de outras espécies - nos próprios lugares ocupados pela produção instituidora, cuja lógica é a de controlar a produção e os usos do produto. Na situação presente, as instituiçóes religiosas e os artistas podem estabelecer transaçóes segundo regimes de ação em que se tornam preponderantes as qualidades que descrevem esta zona da tática. Essa plasticidade permite uma maior inclusividade, quanto à diversidade de linguagens, e é a garantia de um intervalo de autonomia entre o capital simbólico religioso e o medium artístico. Os resultados podem ser inesperados.

\section{Epílogo}

O itinerário percorrido pode contribuir para a construção de uma abordagem compreensiva capaz de dar conta da emergência de campo novo, para além da tensáo e do conflito, no quadro das transaçóes que se estabelecem entre as instituiçóes religiosas e o campo artístico. Os lugares desse encontro têm as qualidades próprias dos lugares-fronteira, uma vez que permitem a transação entre mundos diferentes - incluem o conflito, mas também o compromisso, a troca e a cooperação. Desenham-se aí dinâmicas sociais novas.

De entre os modelos teóricos explorados, merece particular atenção o que emerge da antropologia de Michel de Certeau. Em um contexto em que 
se abre um espaço amplo à plasticidade própria das táticas de reutilização, os objetos do crer podem sofrer profundas remodelaçôes, com resultados não previstos pelas instituiçóes que tinham poder estratégico sobre a construção de ortodoxias e ortopraxias. As resistências ou os desvios em relação a uma memória autorizada não devem ser vistas, apenas, sob o ângulo de uma teoria da vanguarda ou uma sociologia das minorias. Deve falar-se antes, usando a figura do paradoxo sugerida por Michel de Certeau (1990, p. XLIIIs), da marginalidade de uma maioria. Isto porque essas artes de fazer são incorporadas na zona de elasticidade das práticas culturais e não em um quadro dissidência ou simples obsolescência (perspectiva que era bastante recorrente em algumas teorias da secularização até aos anos 1990). Estas artes de fazer, próprias da zona da tática, são também criadoras de sentido. Em um quadro de autonomia de esferas, as instituiçóes e grupos religiosos podem encontrar nas mediçôes artísticas um lugar-fronteira que permite uma zona de contato com os indícios de sacralidade deslocada ou difusa. Como observava Balandier (1985, p. 205), no seu ensaio sobre poder e modernidade, a remissão para um horizonte de sacralidade valida simbolicamente as experimentaçóes culturais, sociais e políticas que têm a ambição de serem criadoras de sentido.

\section{Referências}

ADAMS, J. L. The Place Where You Go to Listen: In Search of an Ecology of Music. Middletown: Wesleyan University Press, 2009.

ADORNO, T. W. Vers une musique informelle. In: Quasi una fantasia: Essays on Modern Music. London: Verso, 1994.

Alienated Masterpiece. The Missa Solemnis. In: Essays on Music. London: University of California Press, 2002.

APPADURAI, A. Modernity at Large: Cultural Dimensions of Globalization. Minneapolis: University of Minnesota Press, 1996.

BALANDIER, G. Le Détour: Pouvoir et modernité. Paris: Fayard, 1985.

BASTIDE, R. “Anthropologie religieuse”. Encyclopaedia Universalis II. Paris, 1968, p. 65-69. BBC. John Tavener on Webern, “the most spiritual composer who ever lived”. Disponível em: <http://www.bbc.co.uk/programmes/p04pddst>. Acesso em: 16 jun. 2016. 
BELLAVANCE, G. "L'autonomie de l'art à l'ère de l'autonomie de tout. Anomie esthétique et souveraineté de l'art dons la modernité". Société, n. 15-16, 1996, p. 157-201.

BOULEZ, P. Jalons (pour une décennie): dix ans d'enseignement au Collège de France, 1978-1988. Paris: C. Bourgois, 1989.

BOURDIEU, P. Les Sciences humaines et l'œuvre d'art. Bruxelles: Connaissance, 1969.

BROWNSTONE, G.; ROUET, A. L'Eglise et l'art d'avant-garde: de la provocation au dialogue. Paris: Albin Michel, 2002.

BURKE, P. Cultural Hybridity, Cultural Exchange, Cultural Translation: Reflections on History and Theory. Cambridge: Polity Press, 2013.

CAILLOIS, R. L'Homme et le Sacré. Paris: Gallimard, 1950.

CANCLINI, N. G. Diferentes, desiguales y desconectados: Mapas de la interculturalidade. Barcelona: Editorial Gedisa, 2004.

CARvalho, M. V. de. Pensar é morrer ou o Teatro de Sáo Carlos na mudança de sistemas sociocomunicativos desde fins do séc. XVIII até aos nossos dias. Lisboa: Imprensa Nacional-Casa da Moeda, 1993.

Razão e sentimento na comunicação musical. Lisboa: Relógio d’Água, 1999.

CERTEAU, M. de. Le christianisme éclaté (en collaboration avec Jean-Marie Domenach). Paris: Seuil, 1974.

La faiblesse de croire. Paris: Seuil, 1987.

. L'Invention du quotidien, I. Arts de faire. Paris: Gallimard [1980] 1990.

CHEYRONNAUD, J. Musique, politique et religion: de quelques menus objets de culture. Paris: L'Harmattan, 2002.

CHOUVEL, J-M. “Avec le temps, il n'y a pas de forme sans mémoire...”. In: OLIVE, J-P et. al. Musique et mémoire. Paris: L'Harmattan, 2003. p. 47-56.

DA COSTA, V. Peut-on parler d'une redécouverte de la spiritualité dans l'art contemporain?”. In: COTTIN, J.; GRÄB, W.; SCHALLER, B. (Ed.). Spiritualité contemporaine de l'art. Genève: Labor et Fides, 2012. p. 171-195.

DRABKIN, W. Beethoven: Missa solemnis. Cambridge; New York: Cambridge University Press, 1991. 
DUCHAMP, M. Duchamp du signe: Écrits. Réunis et présentés par Michel Sanouillet. Paris: Flammarion, 1994.

EISENSTADT, S. N. Multiple Modernities. Daedalus, v. 129, n. 1, p. 1-29, 2000.

ELIAS, N. Mozart: sociologia de um génio, Porto: ASA, 1993.

FEUERBACH, L. L'Essence du christianisme. Traducion de l'allemand. Paris: Maspero, 1973.

FÖLLMI, B. "Spiritualité et musiques contemporaines: entre expression personnelle et exigence liturgique”. In: COTTIN, J.; GRÄB, W.; SCHALLER, B. (Ed.). Spiritualité contemporaine de l'art. Genève: Labor et Fides, 2012. p. 277-290.

FORTIN, A. L'exposition du public à l'art. Cahiers de recherche sociologique, v. 28, p. 89-105, 1997

GAUCHET, M. Le Désenchantement du monde: Une histoire politique de la religion. Paris: Gallimard, 1985.

GOTTWALD, C. Bach, Kagel et la théologie de l'athéisme. Harmoniques, v. 4, p. 152-169, 1988.

KAGEL, M. About the "st. bach passion" (Conversation with Werner Klüppelholz). In: SANKT-BACH-PASSION. CD Audivis/Naïve, 2002.

GROYS, B.; WEIBEL, P. (Ed.). Medium Religion: Faith, Geopolitics, Art. Köln: Verlag der Buchhandlung Walther König, 2008.

HABERMAS, J. Theorie des kommunikativen Handels I-II. Frankfurt: Suhrkamp, 1981.

HARTMAN, A. A War for the Soul of America: A History of the Culture Wars. Chicago, University of Chicago Press, 2015.

HEARTNEY, E. Postmodern Heretics: The Catholic Imagination in Contemporary Art. New York: Midmarch Arts Press, 2004.

EINICH, Nathalie. Du peintre à l'artiste: artisans et académiciens à l'âge classique. Paris: Minuit, 1993. 1998.

Le triple jeu de l'art contemporain. Sociologie des arts plastiques. Paris: Minuit,

L'art contemporain exposé aux rejets: études de cas. Paris: Fayard; Pluriel, 2012. 
FESTIVAL TERRAS SEM SOMBRA. [s. d.]. Disponível em: <http://festivalterrassemsombra. org/>. Acesso em: 16 jun. 2016.

ISAMBERT F-A. La sécularisation interne du christianisme. Revue Française de Sociologie, v. 17, p. $573-589,1976$.

KERROS, A de. Sacré art contemporain: Évêques, Inspecteurs et Commissaires. Paris: Éditions Jean-Cyrille Godefroy, 2012.

KÜNG, H. Música y religión: Mozart - Wagner - Bruckner. Tradución del alemán. Madrid: Editorial Trotta, 2008.

LE MONDE. Attack on "blasphemous" art work fires debate on role of religion in France. 18 abr. 2011a. Disponível em: <https://www.theguardian.com/world/2011/apr/18/ andres-serrano-piss-christ-destroyed-christian-protesters >. Acesso em: 16 jun. 2016.

Deux photographies d'Andres Serrano ont été détruites à Avignon. $18 \mathrm{abr}$. 2011b. Disponível em: <http://www.lemonde.fr/culture/article/2011/04/18/la-destructionde-piss-christ-uvre-impie_1509185_3246.html\#i6k17wS23wLSXsEW.99>. Acesso em: 10 jun. 2017.

LEVY-STRAUSS, C. La pensée sauvage. Paris: Plon, 1962.

LIBRERIA EDITRICE VATICANA. Carta do Papa Joáo Paulo II as artistas. 1999. Disponível em: <https:/w2.vatican.va/content/john-paul-ii/pt/letters/1999/documents/hf_ jp-ii_let_23041999_artists.html>. Acesso em: 10 jun. 2017.

Discurso do Papa Bwnto XVI por ocasiáo do encontro com os artistas na capela

Sistina. 21 nov. 2009. Disponível em: <https://w2.vatican.va/content/benedict-xvi/pt/ speeches/2009/november/documents/hf_ben-xvi_spe_20091121_artisti.html>. Acesso em: 10 jun. 2017.

LYOTARD, J-F. Musique et postmodernité. Surfaces, 6, 1996, p. 203. Disponível em: <http:// www.pum.umontreal.ca/revues/surfaces/vol6/lyotard.html>. Acesso em: 16 jun. 2016.

MELUCCI, A. Mouvements sociaux, mouvements post-politiques. Revue internationale d'action communautaire, v. 10, p. 13-30, 1983.

MORGAN, D. Visual Piety: A History and Theory of Popular Religious Images. Berkeley; Los Angeles; London: University of California Press, 1998.

PASTORAL DA CULTURA. [s. d.]. Disponível em: <http://www.snpcultura.org/>. Acesso em: 16 jun. 2016. 
PIETTE, A. Le mode mineur de la réalité. Louvain: Peeters, 1992.

PRADES, J. Persistance et metamorpbose du Sacré. Paris: PUF, 1987.

PÚBLICO. Previsóes para 2016: Romeo Castellucci divide o Rivoli com um espectáculo de choque. 17 dez. 2015. Disponível em: <https:/www.publico.pt/2015/12/17/culturaipsilon/ noticia/previsoes-para-2016-romeo-castellucci-divide-o-rivoli-com-um-espectaculo-dechoque-1717591>. Acesso em: 10 jun. 2017.

REICH, S. Writings on Music, 1965-2000. New York: Oxford University Press, 2002.

ROBINEAU, A. Les nouvelles stratégies sociales des artistes contemporains dans l'utilisation du sacré: le cas de la Symphonie du Millénaire. Religiologiques, v. 22, p. 85-99, 2000.

SAINT-MARTIN, I. Entre commandes officielles, résurgences et provocations: le catholicisme en France face à l'art contemporain. In: BÉRAUD, C.; GUGELOT, F.; SAINT-MARTIN, I. (Dir.). Catholicisme en tensions. Paris: Éditions EHESS, 2012. p. 265-279.

SANTOS, A. Festival Terras sem Sombra de Música Sacra do Baixo Alentejo. Invenire, v. 2, p. 64-65, 2011.

SÃO LUIZ TEATRO MUNICIPAL. Sobre o Conceito do Rosto do Filho de Deus/Sul Concetto di Volto Nel Figlio di Dio. 6 maio 2017. Disponível em: <http://www.teatrosaoluiz. pt/catalogo/detalhes_produto.php?id=591>. Acesso em: 10 jun. 2017.

- Romeo Castellucci. 12 maio 2017. Disponível em: <http://www.teatro municipaldoporto.pt/PT/programa/romeo-castellucci-it-sobre-o-conceito-do-rosto-do-filhode-deus-sul-concetto-di-volto-nel-figlio-di-dio/?categoria=teatro>. Acesso em: 10 jun. 2017.

SCHLOEZER, B. de; SCRIANINE, M. Problèmes de la musique moderne. Paris: Minuit, 1959.

HINE, T. Taboo Icons: The Bodily Photography of Andres Serrano. Contemporaneity: Historical Presence in Visual Culture, v. 4, n. 1, p. 24-44, 2015. <https://contemporaneity. pitt.edu/ojs/index.php/contemporaneity/article/view/141/145>.

SLOTERDIJK, P. Im Weltinnenraum des Kapitals: Für eine philosophische Theorie der Globalisierung. Frankfurt am Main: Suhrkamp Verlag, 2005.

SOLOMOS, M. Stratégies contemporaines de construction de la mémoire musicale. In: OLIVE, Jean-Paul et al. (Ed.). Musique et mémoire. Paris: L’Harmattan, 2003, p. 238-247.

TEIXEIRA, A. Uma política da imagem: leitura antropológica da blasfémia visual a partir de Pierre Legendre. Revista Portuguesa de História, v. 40, p. 143-174, 2008/2009. 
Um mapa para pensar a religiáo. Lisboa: Universidade Católica Editora, 2015.

O compositor entre mundos. Glosas, v. 15, p. 9-10, 2016.

; DELGADO, C. A emancipação do sagrado e a paródia do religioso. Notas exploratórias sobre a criação musical na segunda metade do século XX. Revista Portuguesa de Ciência das Religióes, v. 2, p. 35-62, 2003.

TESSIER, R. Déplacements du sacré dans la société moderne. Culture, politique, économie, écologie. Montréal: Bellarmin, 1994.

WEBER, M. Gesalmmelte Aufsätze zur Religionssoziologie I. Tübingen: J.C.B. Mohr, 1971.

Wirtschaft und Gesellschaft. Tübingen: J.C. B. Mohr, 1985.

XENAKIS, I. Musiques formelles: nouveaux principes formels de composition musicale. In: La Revue Musical. Paris: Ed. Richard Masse, 1963. p. 253-254. Recebido em: 28/02/2017.

\section{Secularity and sacredness in contemporary musical creation: tensions and transactions}

\section{Abstract}

After a period in which secularization was undertaken as a - linear and teleological - hegemonic explanatory model in the social sciences, it became necessary to find, in the context of multiple modernities, other ways of access to the places of religious' reconfiguration. In this context, it became decisive to re-approximate, at different scales, the scientific lenses to the places in which the new relations between the religious sphere and the other social worlds are being built, through the mediation of the displacements of the sacred. This essay explores the domain of contemporary musical creation as a laboratory for the discovery of these new configurations.

Keywords: Secularity. Sacredness. Music. Religion. 